This item was submitted to Loughborough's Research Repository by the author.

Items in Figshare are protected by copyright, with all rights reserved, unless otherwise indicated.

\title{
The world according to iTunes: mapping urban networks of music production
}

\section{PLEASE CITE THE PUBLISHED VERSION}

http://dx.doi.org/10.1111/j.1471-0374.2011.00357.x

\section{PUBLISHER}

(c) Wiley

\section{VERSION}

AM (Accepted Manuscript)

\section{PUBLISHER STATEMENT}

This work is made available according to the conditions of the Creative Commons Attribution-NonCommercialNoDerivatives 4.0 International (CC BY-NC-ND 4.0) licence. Full details of this licence are available at: https://creativecommons.org/licenses/by-nc-nd/4.0/

\section{LICENCE}

CC BY-NC-ND 4.0

\section{REPOSITORY RECORD}

Watson, Allan. 2019. "The World According to Itunes: Mapping Urban Networks of Music Production". figshare. https://hdl.handle.net/2134/21415. 
The World according to iTunes: Mapping Urban Networks of Music Production

\author{
Allan Watson \\ Department of Geography \\ Staffordshire University \\ Stoke-on-Trent \\ Staffordshire ST4 2DE \\ UK \\ a.watson@staffs.ac.uk
}




\title{
The World according to iTunes: Creative Project Ecologies and the Global Urban Networks of Digital Music Production
}

\begin{abstract}
A)
This paper explores the global urban networks formed through creative project ecologies within the global recorded music industry. The paper presents a social network analysis in which recorded music albums are viewed as temporary market-based projects that bring together teams of skilled creative individuals in recording studios across the globe. New tools and techniques for networking studios in geographically distant locations give mobile musical creatives the ability to coordinate musical recordings on a global scale, resulting in new relational geographies of music production. The analysis assesses the connectedness of cities and determines the centrality and power of cities within networks of production for the UK and US digital music markets. The main finding is the dominance of an Anglophone triad of global cities consisting of New York, Los Angeles, and London, which mediate global networks of musical recording.
\end{abstract}

\section{Key words (A)}

Global City, Global Urban Networks, Project Ecologies, Social Network Analysis, Music Industry, Recording Studios 


\section{Introduction (A)}

Considered as the elementary units of collective commercial agency, in economic geography firms have been largely unproblematised as unitary and coherent actors (see Maskell 2001; Taylor and Asheim 2001). As Grabher (2004a) suggests, economic geography research at the meso-level on networks has largely been focused at an inter-organizational level. This has particularly been the case in much of the research being undertaken on world city networks, which has to date largely focused on the role of advanced producer services firms and their transnational office networks (see Sassen 2000 2001; Taylor 2004). It is typical of such research that other overlapping social networks, and the individual actors that constitute them, are uncritically subsumed into inter-firm networks. Ettlinger (2003) argues that this top-down strategy excludes the people involved in the daily practices of work, and leads to an 'ecological fallacy' whereby it is presumed that what holds for firms in networks also holds for individual actors. For Grabher (2002a), the integrity of the firm as the basic analytical unit is being increasingly undercut by organizational practices that are built around projects -that involve a multiplicity of organizational and personal networks. These arguments have important implications for research into the formation of global urban networks of world cities. While it is now widely accepted that cities do not have power in themselves, but rather find power in the global urban networks in which they are embedded (i.e. their power is relational), recent research on project working highlights that there are agents of network formation other than firms that need to be considered - agents that are crucial for cities to achieve 'global reach'. For cities 
to 'project' their power over distance the successful enrolment of these agents in networks is crucial (Smith 2007).

Social network analysis provides a set of tools that enable the researcher to empirically assess the centrality and power of cities, through the analysis of actors and their networks. This paper provides an examination of global urban networks that is based on the real social connections occurring through project work, i.e. relational data linking cities with other cites rather than on attributional data for specific cities. The paper is concerned with the production of music, which provides a particularly revealing focus for research due to the ways in which music production is caught up in multiple layers of networks (Connell and Gibson 2003) involving a wide range of actors, particularly given the rise of new internet technologies enabling enhanced networking over geographical space. Specifically, the paper examines the real working flows that occur between recording studios, based in cities across the globe, when they are part of temporary global creative projects that are brought together to produce recorded music albums. The end result is a global geography of music production as indicated through the interdependencies between projects, personal and professional networks, and localities on which projects are built. Grabher (2002a 2002b) terms these interdependencies project ecologies.

To begin, this paper considers the production of musical recordings as a form of market-based temporary project work, with a specific focus on the musical recording process, skilled creative labour and technology, personal and 
professional networks and reputation. It then describes a social network analysis that defines the global urban networks formed by the creative project ecologies operating in the recorded music industry, assesses the level of connectedness of cities, and employs a number of measures to determine centrality and power of cities within networks of production for digital music markets.

\section{Musical recordings as project-based working (A)}

Projects can be defined as systems of production that are constituted by different skill holders; economic, social and cultural agents with specialized and complementary competencies)collaborating over a pre-determined period in order to complete a pre-specified and usually complex task (Lundin and Söderholm 1995), where the complexity of the task necessitates the coordination of multidisciplinary skills that it is not economically efficient to bring together on a permanent basis (Lorenzen and Frederiksen 2005). Such temporary project systems are not a new phenomenon, having always been present in certain industries (Asheim 2002). This has particularly been the case in those industries now considered as involving 'old media', including the film industry (see for example Faulkner and Anderson 1987; DeFillippi and Arthur 1998; Blair et al. 2001) and the recorded music industry. In the case of the latter, every new music album, whether physically produced on a CD or as produced as a digital product, can be seen as a discrete product innovation with new content, which is created in a temporary project that brings together highly specialized complementary human resources, including musicians, studio producers and engineers, as well as sales and marketing people (Lorenzen and Frederiksen 2005). With the rise of 'new 
media', focused around innovative new technologies and the internet, we are increasingly seeing even more flexible arrangements for project-based working (see Christopherson 2002; Grabher 2002b). The technologies and practices of these new media are now also inevitably cross-fertilizing with old media industries, impacting on the dynamics of project-based working. In the case of the recorded music industry, the potential for project-based production that spans geographic space has undoubtedly been enhanced by new internet technologies. However, it is important to note that there is a materiality to the mobility that stretches further back than the widespread introduction of the internet. Musical knowledge has always moved within and between cities through mobile creatives, including musicians and DJs, producers and music industry executives (Watson et al. 2009). Recordings have also always been mobile, having been sent and continuing to be sent throughout the world to be mastered and mixed in different studios by specific engineers. It is these two types of mobility - physical, in terms of labour movement, and virtual, in terms of recordings being distributed by digital means - which enable project-based working in the music industry on a global scale.

The recording process $(B)$

The ways in which the process of creating a musical recording constitutes a creative project is perhaps best elucidated by first considering the stages in the musical recording process, with particular reference to key process and the skills required for them. The first stage in the process is the act of recording the 'live' musical performance by the musicians in the recording studio. As such, it is recording studios that are privileged to the most intimate moments of musical 
creativity and emotive performance, with the insulated space of the studio that gives musical creatives the conditions required to experiment and create music (Watson et al. 2009). It is important to note that these creative moments are produced not by the musician alone, but through relations between musicians, producers, and engineers (Gibson 2005). While musicians are recognized as the creators of music, record producers, who control and supervise the recording process, and studio engineers, who are skilled in operating the complex equipment of the recording studio, act as cultural intermediaries (see Hennion 1989), upon whom the ability of musicians to make music is dependent (Shuker 1994; Pinch and Bijsterveld 2004). For Horning (2004), the recording studio is a site of collaboration between 'technologists', the producers and engineers with the knowhow to operate the highly technological equipment in studios, and artists, where maximum creativity requires a symbiotic relationship that requires skills which are at the same time both technical and artistic.

Multi-track recording is the most common technological method of recording popular music. This is a method of sound recording that allows for the separate recording of multiple sound sources to create a cohesive whole. Multiple musical instruments and vocals can be recorded, either one at a time or simultaneously, onto tracks which can be individually processed and manipulated to produce the desired results. Originally undertaken using analogue tape-based equipment, multitrack recording is now largely undertaken using digital equipment that uses tape storage, or using multi-tracking software on computers with digital recordings stored on hard disk. As Warner (2003) notes, the technologies used by these skilled creatives to produce music are in a state of continuous development, 
particularly in the case of popular music. Whereas the earliest tape-based machines allowed for four music tracks, new computer-based systems allow for a potentially unlimited number of tracks, bringing new levels of complexity to the recording process.

Following the main recording stage, the next stage is audio mixing. This is the process by which the variety of tracks recorded by musicians are combined together into a single stereo recording. During this process, elements of the source recordings are adjusted and effects added, in order to finalize the balance of sound within recordings. The process of mixing has traditionally been undertaken using a mixing console, with associated processor and effects plug-ins. However, as with multi-track recording, more and more studios are now moving to digital computerbased systems. The availability of these new technologies mediate creative actions and offer the potential for high levels of innovation and creativity (Warner 2003). Thus creative talent is crucial to the performance of the recording studios, being required to know how to operate technical complex equipment, but also to have the tacit knowledge (knowledge carried by an individual that is difficult to transfer elsewhere) and craft skills, gained from experience, which are indispensable to artistic creativity within the studio (see Horning 2004). As Leyshon (2009) suggests, technical expertise must also be combined with the skills and musical ambitions of the clients, as well as emotional support and encouragement for the creative process - Leyshon terms this emotional labour. Certain studios are known for the experience and skill of staff, particular acoustic qualities and the quality of recording equipment. Certain 'sounds' may become associated with particular producers or engineers. In the 1960s in Jamaica, for example, the recording studio 
and record label 'Studio One' would become central to the development of the distinct sounds of reggae music. Its characteristic sound would come from the way the studio was engineered by producer Clement Seymour 'Coxsone' Dodd. Dodd balanced sounds in a unique way based on the studio room, which meant that his sound could not be replicated elsewhere. He also chose key musical directors, and by keeping them on a wage helped to retain a distinctive sound.

The final part in the production process for recorded music is the post-production process of mastering. This is the process whereby the final mix of the recorded audio is prepared and transferred to a master copy on a data storage device, from which all subsequent copies are produced. In the case of release for digital music markets, with which this paper is concerned, digital masters are used. However, while digital storage of masters is now pervasive throughout the industry, much of the mastering process is still undertaken using analogue processing equipment due to issues of sound quality with digital equipment. Mastering is a highly specialized and geographically-concentrated process, and as I shall subsequently demonstrate later in the paper, the Anglo-American market is dominated by a handful of studios with a reputation for high-quality mastering (Leyshon 2009).

Project ecologies in the recorded music industry (B)

Following the definition given by Grabher (2002a 2002b), the ecology of a project is understood to involve a range of different firms and organizations, individual actors, technologies, spaces and places. Whereas much of the literature on projects has focused upon 'project teams', in which skilled actors are employed within the same 
firm, in the music industry, projects are carried out mainly in the market. In 'marketbased' projects, participating skill holders are employed in different firms or may be freelancers (Lorenzen and Frederickson 2005). It is evident from the above discussion on the recording process that each stage of the recording process requires skilled labour, in the form of studio producers and engineers, with the appropriate technical skills and tacit knowledge. The skilled actors working on a recording project are typically not employed on a permanent basis by a single record company or recording studio; rather, they are a combination of freelance and studio-employed/contracted producers and engineers, generally with no long term association with any one record company. They carry out their work in creative project networks that transcend the boundaries of firms (Lorenzen and Frederickson 2005). It is these individuals, with unique skills and high levels of creativity, that are the main prerequisite for the maintenance and renewal of these creative networks (Törnqvist 2004) and thus for project-based working in the music industry. As DeFillippi and Arthur (1998) assert, fluid project ecologies challenge the idea of core competencies existing as internal resources, and the knowledge base required to produce a recorded musical product is largely external to the record company, and often is not internal to the industry (Asheim 2002). For example, increasing synergies are to be found between music companies and ICT firms, such as those described by Power and Jansson (2005) in a growing music services industry in Stockholm, exploiting the opportunities offered by new internet and mobile technologies and digital music platforms.

In most cases it is the record company that plays the co-ordinating role in bringing together creatives onto projects as required for a particular recording project. In 
order to produce successful products on increasingly global markets, record companies must be able to draw on relevant knowledge bases for the relevant part of the value chain in production (Asheim 2002), and draw essential competencies into the firm as individual projects require. As the recording industry cannot ultimately control what is going to be commercially successful, larger firms often have attempted to monopolize access to the best recording facilities and most talented engineers and producers (Negus 1992). However, since the 1970s, new sound recording technologies have broken monopolies (Jones 2002), brought about democratization of the recording process, and undermined the position of many recording studios (see Leyshon 2009). Studios now largely act as an independent service within the contemporary recorded music industry, with many owned and operated by entrepreneurial producers and engineers (Watson et al. 2008). This has had important repercussions for project work in the music industry by increasing the number of studios and level of skilled studio creatives available to firms and musicians.

Musical recordings are essentially 'one-off' projects that bring together, temporarily in space and time, a group of skilled creatives to undertake a project with the definite end product of a music track or full album. Recording projects then can be considered as resembling a more conventional form of 'managed' project than the 'self-organized' projects that characterize 'new media' (see Grabher 2002b) in that it has a budget allocated by the record company, who also appoints a manager who oversees the project. Management of these projects is challenging, as the record company needs to retain control of the project and ensure satisfactory progression whilst at the same times allowing the creative talent - the musicians 
and studio producers and engineers - the creative 'freedom' required to produce the required standard of product. When to terminate the project is, however, a record company decision, whether this is once the project is completed, or if it is considered to be progressing unsatisfactorily. Although these projects are essentially one-offs, as personal networks are built, further projects may be undertaken involving recurrent collaboration. Grabher (2002c) suggests that project operate in a 'milieu' of recurrent collaboration that, after several project cycles, fills a pool of resources and 'gels' talent into latent networks. This is due to the way in which new projects tend to draw on core members of successful prior projects. Grabher (2002b 2002c) emphasizes that such chains of repeated co-operation are held together, or indeed cut-off, by the reputation members gained, or lost, in previous collaborations. Often musicians make choices for themselves regarding the cost and location of production (Jones 2002) and the producers and engineers who will work on their recording project. This decision will be down to a combination of previous experience on projects, personal and professional networks, and the individual reputation of producers and engineers. For Grabher, individual creative reputation within project-based working is built on the presentation of a series of skill sets:

"Reputation in project organization refers, first and foremost, to the techniques of the trade, particularly in settings like media, in which crucial skills are hardly codified into certificates. Second, the success of projects, more generally, depends on co-operative attitude, reliability and other inter-personal skills that, rather than objectivized in formal degrees, are bound to personal experience" (Grabher 2002c: 209) 
Activities in temporary projects are dominated by individual knowledge embodied in highly mobile project members (Asheim 2002; Grabher 2002b). As these embodied creative knowledges are for sale on the labour market, any competitor can potentially draw on competencies that have developed (see Lam 2000). Individual skills are transferred between projects as project members typically collaborate simultaneously with a wide range of firms (Grabher 2002b). Networking is then the emblematic practice in project ecologies (Wittel 2001). However, as well as professional networks and communities of practice revolving around firms, project ecologies also involve personal networks that "symptomatically efface the distinction between private and business" (Grabher 2004a: 105), stretch out beyond the pattern of actual production networks, and provide lasting support for the individual actors in ecologies (Grabher 2004b). In project-based working it is often personal networks, rather than formal firm contractual networks, that provide the basic social infrastructure for putting together a project team (Grabher 2002a). Grabher (2002b) notes that personal networks seem to be strongly, although not exclusively, rooted in a particular locality, particularly in the creative realm. Spatial agglomerations in the music industry are indeed important due to the way in which they function not only as pools of capital and skills, but also as arenas of socialization (Scott 1999). Previous research on the music industry has highlighted the importance of geographical proximity and face-to-face interaction in the development of personal and social networks and relationships in the music industry, the dynamics of which are built around an informality that blurs the business-social divide (Watson 2008) and transgresses the boundaries of the firm 
(see Pratt 2000). As such, spatial agglomerations function as potent frameworks of cultural reproduction (Scott 1999) and learning.

It is important, however, to note that these milieux are not geographically constrained. For Asheim (2002) the continued importance of localized learning can be challenged by the increasing importance of temporary project working. Personal and professional creative networks in both 'old' and 'new' media are increasingly spanning the globe, resulting in geographically far-flung project collaborations, such as those identified by Cole (2008) in a study of animated film production in Europe. In the case of the music industry, new technologies that network studios in geographically-distant locations enable musical recording projects to be coordinated on a global scale and so allow for projects to draw on creatives in geographically-dispersed locations. Ties between record companies, musicians, and specialized producers and engineers reach out between musically creative cities across the globe. Thus, we are seeing the development of new relational geographies of music creativity across multiple spatial scales and the formation of global urban networks of musical production.

\section{Data collection (A)}

It is the project rather than the firm that forms the basic analytical category of the analysis presented in this paper. The projects on which the analysis focuses are recorded popular music albums, defined as a group of audio tracks with a generally consistent track list across the different territories in which it is released. Each album has its own temporary project ecology, consisting not only of firms (record 
companies), but also localities - recording studios in particular cities, and the professional and personal networks of the musicians and studio producers and engineers - 'creative labour'. Within these ecologies, elements of creative labour may be fixed in particular studios, with recordings being transferred digitally, or this labour may be mobile between studios in different cities. It is these movements, of both labour and recordings, which are the connections that form the global urban networks of musical production within the recorded music industry. Thus, in collecting data for the social network analysis described in the following section of the paper, an event-based strategy has been employed in which network boundaries are drawn by including actors who participate in a defined set of activities occurring in specific times and places (see Knoke and Yang 2008). Each of these events, in this case temporary music industry projects (albums), has their own distinct production network, varyingly dispersed in terms of their geography. An example of a geographically dispersed network is shown in Figure 1, for the album 'Tonight' by Franz Ferdinand, released on Domino Records/Epic Records in January 2009. The network of recording for this particular album is dispersed across six studios in six cities, including cities in the UK (London, Bristol, Glasgow), the US (Los Angeles, Phoenix) and Canada (Vancouver). By including multiple events (albums) in the network analysis, it is possible to produce a comprehensive and inclusive network, in which many distinct networks overlap with one another.

Databases of recording information for albums, consisting of information on the recording studios used, and the creative labour involved in the recording, were constructed based on albums appearing in the top 10 iTunes download charts, for 
the UK and US digital music markets, during the first six months of 2009. Not withstanding the 'crisis' in the music industry that has resulted from the introduction of digital software formats (see Leyshon 20012003 2009; Leyshon et al. 2005; also Hughes and Lang 2003), digital download sales charts were chosen for use in this study due to the way in which the digital music market is forming an increasingly important part of the global music market. In January 2009 digital platforms accounted for around 20 percent of global recorded music sales, with the digital revenues of international music companies growing by an estimated 25 percent in 2008 to $\$$ US3.7 billion (IFPI 2009). iTunes sales charts were chosen for analysis because iTunes is the leading player in the online downloads market, and in 2008 became the largest music retailer in the US. iTunes top-10 music sales charts are published online and are continuously and automatically updated, and are available for most of the major national digital music markets. This allows comparisons to be made between a range of national digital music markets. In this paper, comparisons are made between the UK and US digital music markets. These two markets were chosen for analysis due to the way in which AngloAmerican music continues to dominate global music markets and influence musical cultures across the world (Colista and Leshner 1998). For reasons of practicality the continuous updates to the charts could not be followed on a constant basis, and therefore the charts were analysed on a weekly basis. In sampling only that music appearing in the top-10 of the iTunes charts, the study is inevitably focusing predominantly on those artists and genres of music that have been prioritized by the global music industrial system (see Negus 1996). However, this does put the study in a position to connect the success of an artist and a musical recording, in terms of sales, with the systems of production that put them in the position to be 
internationally and globally popular in the first place (see Power and Hallencreutz 2007).

Data was sampled between $1^{\text {st }}$ January 2009 and $31^{\text {st }}$ June 2009. Only full albums released in this time period and up to one year before, and including newly released material, were included in the sample. EPs (releases containing a smaller number of tracks than a full album), compilations, 'greatest hits' compilations, and albums originally released over one year before the sampling date, were not included. The final databases contain data on 53 albums from the UK download charts and 52 albums from the US download charts respectively. The data are coded as non-directional, i.e. there is no distinction made between 'senders' and 'receivers' in relationships, rather they are considered to involve mutual exchange. The data produce two symmetrical and valued matrices, one for UK networks of production and one for US networks of production, with the matrices linking 36 cities and 43 cities across the globe respectively. Inevitably a significant amount of overlap occurs between the two databases.

\section{Social network analysis methodology $(A)$}

In their social network analysis of the world city system, based upon data on multinational corporations but with many parallels to this study, Alderson and Beckfield (2004) assess the power of world cities based upon a number of measures of centrality: closeness, betweeness, outdegree and indegree. For the first of these two measures, a symmetric dichotomous matrix is used. As Taylor (2006) suggests, this makes the measures of little interest in understanding inter- 
city relations. The latter two measures are of more interest in understanding these relations, in that it distinguishes between connections that are 'sent' or 'received'. Alderson and Beckfield associate these two measures with power and prestige respectively. However these measures require an asymmetric valued matrix of directional data, whereas the data collected for this analysis produces symmetric valued non-directional data matrices, and therefore it is not possible to calculate outdegree and indegree centrality. In order to make best use of the symmetric valued matrices developed in this study, this analysis employs two different measures to assess centrality and power in each of the urban networks. The first measure used is Bonacich's power-based centrality measure (see Hanneman and Riddle 2005). In applying this measure to urban networks, centrality and power in the network is a function of the connections of the cities to which a particular city is connected. The more connected the cities to which a particular city is connected to, the more central the city is. The less connected the cities to which a particular city is connected to, the more powerful the city is, and the less connected cities will be more dependent on it. The second measure used is flow betweeness. This measure is based on the proportion of the entire flow between two actors, through all of the pathways connecting them, which occurs on paths of which a given actor is a part. The measure adds up how involved the actor is in all of the flows between all other pairs of actors, as a ratio of the total flow betweeness that does not involve the actor (Hanneman and Riddle 2005). Betweeness centrality is an important indicator of control of information exchange and resource flows within a network (Knoke and Yang 2008), as the measure ascertains the extent to which an agent can play the part of a 'gatekeeper' with a potential for control over others (Scott 1991). Although they may not necessarily have the most connections to 
other cities, those cities with a high degree of flow betweeness centrality are considered to be the most important mediators in the urban network. These cities are better situated than other cities as a result of the position that they occupy in the network (Alderson and Beckfield 2004). A core-periphery analysis is also undertaken on the valued data matrices to identify those cities belonging to the core of the network and those which belong to the periphery. The social network analysis presented in this paper was undertaken using the UCINET software (Borgatti et al. 2002). The network visualizations provided are derived through the embedded NetDraw visualization tool.

\section{Global urban networks of musical production (A)}

Table 1 ranks the top five cities based on the release of albums into the UK digital music market. The figures given are based on the number of albums for which studios in the city were involved in the recording 'project' expressed as a percentage of the total number of albums captured from chart data. Based upon this, London is shown to be the pre-eminent centre for the output of salessuccessful recorded music into the UK digital music market. Studios based in the city were involved in the recording projects for over 50 percent of all the albums captured in the data. Los Angeles and New York, with 38 percent and 36 percent respectively, trail behind London but are far ahead of a second tier of smaller UK, European and US cities. Many other cities with individually smaller levels of output make up a third-tier of production. The dominance of the global city triad in terms of sales-successful output for the UK digital music market is clearly highlighted by these figures. 
Table 2 ranks the top five cities based on output of albums into the US digital music market. In the case of the US digital music market, Los Angeles is shown to be the pre-eminent centre for the output of sales-successful music, with its studios involved in the recording of almost 60 percent of all the albums captured in the data. It is closely followed by New York, with New York studios involved in 46 percent of the albums sampled. Contrasting with the case of the UK digital music market, London is significantly behind both Los Angeles and New York in terms of sales-successful output into the US digital music market, accounting for 25 percent of the albums sampled. These cities are followed in the top 5 cities by two more US cities, Nashville and Portland (MN), accounting for 10 percent and 8 percent respectively. This data once again highlights the dominance of the global city triad of Los Angeles, New York and London.

Connectivity in global urban networks $(B)$

While this output data is useful in providing a hierarchy of cities based on levels of production, it tells us nothing about networks of production between cities. The data gathered on connectivity, based on the links between cities occurring as part of creative projects, is more informative as to the configuration of global networks of musical production. The data for connectivity for networks of production for the UK digital music market further highlights the dominance of the triad of London, New York and Los Angeles. Table 3 ranks the top cities based on their total number of connections to other cities. London, New York and Los Angeles 
dominate the rankings as the three most connected cities, with around three times the number of connections of the fourth placed city, Bristol.

All three cities have their highest connectivity to each other, and all of the other cities have their highest connectivity with one or more of these three cities. The strongest link between individual cities is shown to be that between New York and Los Angeles, very closely followed by the connection between London and Los Angeles. The remainder of the list consists of other smaller UK, US and European cities. Figure 2 provides a visual representation of the global urban networks formed by these connections. The visualization displays the triad of London, New York and Los Angeles lying at the centre of network, surrounded by a web of less connected cities whose role as music recording centres is articulated through the three highly connected global cities.

Table 4 ranks the top cities within the global urban networks of production for the US digital music market, based on their total number of connections to other cities. The US global city dyad of New York and Los Angeles are shown to dominate the rankings of the most connected cities. Both cities have over twice the number of connections of the third placed city, London. The two cities are shown to have an extremely strong level of connection to each other when compared to the strength of their links with other cities, having around four times more connections with each other than they have with London. Figure 3 provides a visual representation of the global urban networks formed by these connections. The visualization displays the dyad of New York and Los Angeles lying at the centre of network of production. Contrasting with the global network for the UK digital market shown in Figure, 
London does match these two cities in terms of importance at the centre of the network.

Centrality and power in networks of production (B)

In the urban network of production for the UK digital music market, Los Angeles, whilst only the third most connected of the cities in terms of total connections, is calculated to have the highest degree of centrality, i.e. has the most connections to other cities with a high degree of connectivity, marginally above both New York and London. Although London accounts for the output of many more albums into the UK digital music market than Los Angeles and New York (52 percent of albums, compared to 38 percent and 36 percent respectively, by this measure it is the least central of the dominant three cities. However, in terms of power in the urban network, i.e. in terms of many cities with low degrees of connectivity being dependant upon the city, London is calculated to be the most powerful city in the network, very closely followed by New York. Los Angeles is the third most powerful city, but is shown to be far less powerful than both London and New York. London is also calculated to be the most important mediating city in the network based upon the flow betweeness centrality measure, significantly more important than New York, which is turn is a significantly more important mediator than Los Angeles. These results, outlined above are summarized in Table 5, are indicative of London's dominance as the most important city within the global urban network of production for the UK digital music market. 
In the urban network of production for the US digital music market, New York is shown to score highest on all three centrality measures (Table 6). This is despite having a weaker album output than Los Angeles (involvement in 46 percent of total albums compared to 58 percent), and only a marginally higher number of connections (54 compared to Los Angeles' 53). Based on the Bonacich measure, New York is calculated to have the highest degree of centrality, i.e. has the most connections to other cities with a high degree of connectivity, although it shown to be only marginally ahead of Los Angeles. Both cities have much higher centrality rankings than London, which in turn is significantly ahead of the fourth-placed city, Atlanta. New York is also shown to be the city with the most power in the urban network, i.e. in terms of many cities with low degrees of connectivity being dependant upon the city. By this measure, New York is shown to be much more powerful than Los Angeles. Los Angeles is shown to be only marginally ahead of London in terms of power in the network, despite accounting for a much higher output of albums (involvement in 58 percent of total albums compared to 25 percent) and having many more connections (53 compared to London's 23 ). This highlights London's power over certain weaker cities in the global urban network, cities which New York and Los Angeles may have to go through London to access. New York is also calculated to be the most important mediating city in the network based upon the flow betweeness centrality measure, significantly more important than New York, which is turn is a significantly more important mediator than London. These results are indicative of New York's dominance within the global urban networks of production for the US digital music market. 
A core-periphery analysis for the networks of production for the UK digital music market gives a core that contains nine of the 36 cities involved in the production of the musical outputs included in this analysis. Along with the three dominant cities of London, New York and Los Angeles, is a second-tier of core cities: Atlanta, Bristol, Dublin, Glasgow, Miami, and Stockholm. These cities have relatively strong ties to the three dominant cities, and to each other, when compared to peripheral cities. The same analysis for the networks of production for the US digital music market gives a core that contains just five of the 43 cities included in the data. New York, Los Angeles and London are present in the core; they are joined by Atlanta and Portland (MN), the only second-tier core cities. All other cities in the network have relatively low connections with the core cities and each other.

Prestigious studios in prestigious cities (B)

As stated previously, the data used in the study is non-directional, in that it does not distinguish between connections to and from a city. Indeed, it is assumed that links between cities involve mutual exchange and communication in both directions. Due to this, it has not been possible to follow Alderson and Beckfield (2004) in calculating outdegree and indegree centrality, which they associate respectively with the power and prestige of cities. However, although it is not directly measured in the data, there is one particular part of the musical recording process where cities may perhaps be considered 'senders' and 'receivers': the mastering of recordings. Here recordings are sent via electronic means, to be mastered in specific studios, which undertake mastering for an unbalanced share 
of the recordings produced. Thus this key production process plays an important role in concentrating production networks through certain key cities.

In terms of the UK digital music market, the most significant mastering studio is Metropolis Studios based in London, followed by Sterling Sound based in New York (see Table 7). Together, these two mastering studios account for one-third of the total number of albums sampled. In the top five these studios are joined by Bernie Grudman Mastering (Los Angeles), Masterdisk (New York), and Gateway Mastering (Portland, MN). Together these five studios account for 55 percent of the total number of albums sampled. This highlights the concentration of this key process in particular studios in particular cities. In terms of the US digital music market, it is a US-based studio that is prominent. Sterling Sound, based in New York, dominates the list of key mastering studios (Table 8), accounting for 28 percent of albums. It is followed by Bernie Grudman Mastering (Los Angeles) Gateway Mastering (Portland, MN), Marcussen Mastering (Los Angeles) and Metropolis Studios (London). Together these five studios account for 66 percent of the total number of albums sampled, suggesting even greater concentration of the mastering process than that found in the networks of production for UK digital markets.

We might consider these select cities, to which a disproportionate amount of recordings are 'sent' as prestigious cities, because they receive many directed connections. As Alderson and Beckfield (2004) describe, these are the cities that are sought out by other cities, have ties directed to them, and are chosen over others. It is perhaps unsurprising that the three most central and powerful 
mediating cities as indicated by the centrality measures - London, New York, and Los Angeles - are also the three most prestigious cities based on these connections. There are two central reasons for the concentration of the process in these cities. Firstly, technology is central to the mastering process, and therefore those studios that can afford to invest the latest technology will be most desired by potential clients. However, having the most desired technology is not enough alone. As described previously, the process requires studio engineers with the appropriate level of skill and creativity to employ the technology to best effect. All of the major mastering studios have mastering engineers contracted to them. Clients not only seek to use particular studios, but also to use particular mastering engineers based upon there reputation. For example, Ted Jensen, chief mastering engineer at Sterling Sound in New York, alone accounts for 15 percent of the total number of albums sampled from the US digital market, while mastering engineers John Davis and Tim Young of Metropolis Studios in London, together account for the mastering of almost 20 percent of the total number of albums sampled from the UK digital market. Bob Ludwig of Gateway Mastering in Portland alone accounts for 10 percent of the total number of albums sampled from the US digital market, and 7 percent of those from the UK digital market. The prestigious nature of certain studios, and thus of particular cities, can then be directly attributed to the skilled engineers that are working in the studios and living in the cities. Large global cities such as London, New York, and Los Angeles Cities act as magnets for these talented individuals from across the globe (Scott 1999), in which many both work and live. 


\section{Conclusions (A)}

This paper has highlighted the role played by market-based temporary projects in production within the music industry, and presented a social network analysis that reveals the global geographies of music production, as indicated through project ecologies - the interdependencies between projects, personal and professional networks, and localities on which projects are built. In market-based projects in the music industry, participating skill-holders carry out their work within creative project networks that transcend the boundaries of firms and even of the music industry itself. Ties between record companies, musicians, and specialized producers and engineers reach out between musically creative cities across the globe, resulting in the development of new relational geographies of creativity. It has emerged from the social network analysis that the spatial agglomerations of music industry firms, studios, and creatives, in particular key cities remain central to music recording process in the age of digital music markets. This is especially the case for the triad of global cities of New York, Los Angeles, and London, home to very strong concentrations of record companies and recording studios (see Scott 1999; Watson 2008). The main finding of the analysis is the dominance of this Anglophone triad of global cities, the most central and powerful cities within global networks of musical recording.

Leyshon (2009) notes that the long-term failure of UK-based artists to break into the large US market has had a negative effect on UK, especially London-based, recording studios. While the results of this paper do not provide any direct evidence of these negative effects, the analysis of global urban networks of 
recording for the UK and US digital music markets does highlight that the importance of London's recording studios to the UK market is not mirrored for the US market. While London studios dominate the sales-successful output for UK market above both New York and Los Angeles, it falls far behind these two cities in terms of sales-successful output for US markets. Power and Hallencreutz (2007) note that the cultural and knowledge gap between the USA and the rest of the world is potentially the most insurmountable. They suggest that, aside from different business cultures and operations contexts, most foreign musicians and music industry actors lack sufficient personal contacts and local knowledge to access networks in the USA. Building on the findings of this study, this is an interesting area for future research into globally-dispersed project ecologies in the music industry.

The results of the analysis support the earlier assertion that the power of cities is produced in between many actants within networks, and therefore that the successful enrolment of their actants in networks is central to the formation of global urban networks and to the centrality and power of cities. Furthermore, the results suggest that, while many different cities are involved in musical production for UK and US digital music markets, and technologies are increasingly allowing project working between geographically-dispersed creatives, geographicallylocalized knowledge and learning within the major music industry agglomerations remains of central importance to musical production. This challenges the notion of a connection between temporary forms of organization and the spatial disembeddedness of learning and innovation put forward by Asheim (2002). In a time in which new internet technologies dominate production and distribution in the 
media industries, enabling project working and the development of professional and personal networks across multiple geographically scales, it would seem that geography remains alive and well (see also Pratt 2002).

\section{Acknowledgements (A)}

I am extremely grateful to both Michael Hoyler and Phil Hubbard (Loughborough) for providing constructive comments on earlier drafts of this paper, and for their continued support for my research. I would like to acknowledge the financial support of the Department of Geography, Loughborough University, UK, towards the doctorate research which informs this paper.

\section{References (A)}

Alderson, A. S., and Beckfield, J. (2004) 'Power and position in the World City System', American Journal of Sociology, 109 (4), 811-851.

Asheim, B. T. (2002) 'Temporary organizations and spatial embeddedness of learning and knowledge creation', Geografiska Annaler, 84 B (2), 111-124.

Blair, H., Grey, S., and Randle, K. (2001) 'Working in film: employment in a project based industry', Personnel Review, 30 (2), 170-185.

Borgatti, S. P., Everett, M. G., \& Freeman, L. C. (2002) UCINET for Windows: Software for Social Network Analysis, Harvard: Analytic Technologies. 
Christopherson, S. (2002) 'Project work in context: regulatory change and the new geography of media', Environment and Planning A, 34, 2003-2015.

Cole, A. (2008) 'Distant neighbours: the new geography of animated film production in Europe', Regional Studies, 42 (6), 891-904.

Colista, C. and Leshner, G. (1998) 'Travelling music: following the path of music through the global market', Critical Studies in Mass Communication, 15, 181-194.

Connell J., and Gibson, C. (2003) Sound tracks: popular music, identity, and place, London: Routledge.

DeFillippi, R. J. and Arthur, M. B. (1998) 'Paradox in project-based enterprise: the case of film making', California Management Review, 40 (2), 125-139.

Ettlinger, N. (2003) 'Cultural economic geography and a relational and microspace approach to trusts, rationalities, networks and change in collaborative workplaces', Journal of Economic Geography, 3 (2), 145-171.

Faulkner, R. R. and Anderson, A. B. (1987) 'Short-term projects and emergent careers, evidence from Hollywood', American Journal of Sociology, 4, 879909. 
Gibson, C. (2005) 'Recording studios: relational spaces of creativity and the city', Built Environment, 31 (3), 192-207.

Grabher, G. (2002a) 'The project ecology of advertising: task, talents, and teams', Regional Studies, 36, 245-262.

Grabher, G. (2002b) 'Guest editorial’, Environment and Planning A, 34, 1911-1926.

Grabher, G. (2002c) 'Cool projects, boring institutions: temporary collaboration in social context', Regional Studies, 36, 205-214.

Grabher, G. (2004a) 'Learning in projects, remembering in networks? Communality, sociality, and connectivity in project ecologies', European Urban and Regional Studies, 11 (2), 103-123.

Grabher, G. (2004b) 'Temporary architectures of learning: knowledge governance in project ecologies', Organization Studies, 25, 1491-1514.

Hanneman, R. A. and Riddle, M. (2005) Introduction to social network methods, Riverside, CA: University of California, http://faculty.ucr.edu/ hanneman/nettext/

Hennion, A. (1989) 'An intermediary between production and consumption: the producer of popular music', Science, Technology, \& Human Values, 14 (4), 400-424. 
Horning, S. S. (2004). 'Engineering the performance: Recording engineers, tacit knowledge and the art of controlling sound', Social Studies of Science, 34 (5), 703-731.

Hughes, J. and Lang K. R. (2003) 'If I had a song: the culture of digital community networks and its impact on the music industry'. International Journal on Media Management, 5 (3), 180-189.

IFPI (2009) Digital Music Report 2009: New Business Models for a Changing Environment, International Federation of the Phonographic Industry, January 2009, http://www.ifpi.org/content/library/DMR2009.pdf

Jones, S. (2002) 'Music that moves: popular music, distribution and network technologies', Cultural Studies, 16 (2), 213.232.

Knoke, D. and Yang, S. (2008) Social Network Analysis, London: Sage.

Lam, A. (2000) 'Tacit knowledge, organizational learning and societal institutions: an integrated framework', Organization Studies, 21 (3), 487-513.

Leyshon, A. (2001) 'Time-space (and digital) compression: software formats, musical networks, and the reorganization of the music industry', Environment and Planning A, 33 (1), 49-77. 
Leyshon, A. (2003) 'Scary monsters? Software formats, peer-to-peer networks, and the spectre of the gift', Environment and Planning D, 21 (5), 533-558.

Leyshon, A. (2009) 'The software slump?: digital music, the democratization of technology, and the decline of the recording studio sector within the musical economy', Environment and Planning A, 41, 1309-1331.

Leyshon, A., Webb, P., French, S., Thrift, N., and Crewe, L. (2005) 'On the reproduction of the musical economy after the Internet', Media, Culture \& Society, 27, 177-209.

Lorenzen, M. and Frederiksen, L. (2005) 'The management of projects and product experimentation: examples from the music industry', European Management Review, 2 (3), 198-211.

Lundin, R. A. and Söderholm, A. (1995) 'A theory of the temporary organization', Scandinavian Journal of Management, 11, 437-455.

Maskell, P. (2001) 'The firm in economic geography', Economic Geography, 77 (4), 329-344.

Negus, K. (1992) Producing Pop: Culture and Conflict in the Popular Music Industry, London: Edward Arnold. 
Negus, K. (1996) Popular Music in Theory: An Introduction, Cambridge: Polity.

Pinch, T., and Bijsterveld, K. (2004) 'Sound studies: new technologies and music', Social Studies of Science, 34 (5), 635-648.

Power, D. and Hallencreutz, D. (2007) 'Competitiveness, local production systems and global commodity chains in the music industry: entering the US market', Regional Studies, 41 (3), 377-389.

Power, D. and Jansson, J. (2004) 'The emergence of a post-industrial music economy? Music and ICT synergies in Stockholm, Sweden', Geoforum, 35, 425-439.

Pratt, A. C. (2000) 'New media, the new economy and new spaces', Geoforum, 31, $425-436$.

Pratt, A. C. (2002) 'Hot jobs in cool places. The material cultures of new media product spaces: the case of south of the market, San Francisco', Information, Communication and Society, 5 (1), 27-50.

Sassen, S. (2000) Cities in a World Economy, $3^{\text {rd }}$ Edition, Thousand Oaks, CA: Pine Forge.

Sassen, S. (2001) The Global City, $2^{\text {nd }}$ Edition, Princeton, NJ: Princeton UP. 
Scott, A. (1999) 'The US recorded music industry: on the relations between organization, location and creativity in the cultural economy', Environment and Planning A, 31, 1965-1984.

Scott, J. (1991) Social Network Analysis, London: Sage.

Shuker, R. (1994) Understanding popular music, London: Routledge.

Smith, R. G. (2007) 'Postructuralism, power and the global city', in P. J. Taylor, B. Derudder, P. Saey and F. Witlox (eds) Cities in Globalization: Practices, Policies and Theories, London: Routledge, 258-270.

Taylor, M. and Asheim, B. (2001) 'The concept of the firm in economic geography', Economic Geography, 77 (4), 315-328.

Taylor, P. J. (2004) World City Network: A Global Urban Analysis, London: Routledge.

Taylor, P. J. (2006) 'Parallel paths to understanding global inter-city relations', American Journal of Sociology, 112 (3), 881-894.

Törnqvist. G. (2004) 'Creativity in time and space', Geografiska Annaler, 86b, 22743. 
Warner, T. (2003) Pop music - technology and creativity: Trevor Horn and the digital revolution, Aldershot, UK: Ashgate.

Watson, A. (2008) 'Global music city: knowledge and geographical proximity in London's recorded music industry', Area, 40 (1), 12-23.

Watson, A., Hoyler, M. and Mager, C. (2009) 'Spaces and networks of musical creativity in the city', Geography Compass, 3 (2), 856-878.

Wittel, A. (2001) 'Toward a network sociality', Theory, Culture \& Society, 18 (6), 5176. 
Figure 1: Example album project network: Franz Ferdinand 'Tonight' (Domino Records/Epic Records, 2009)

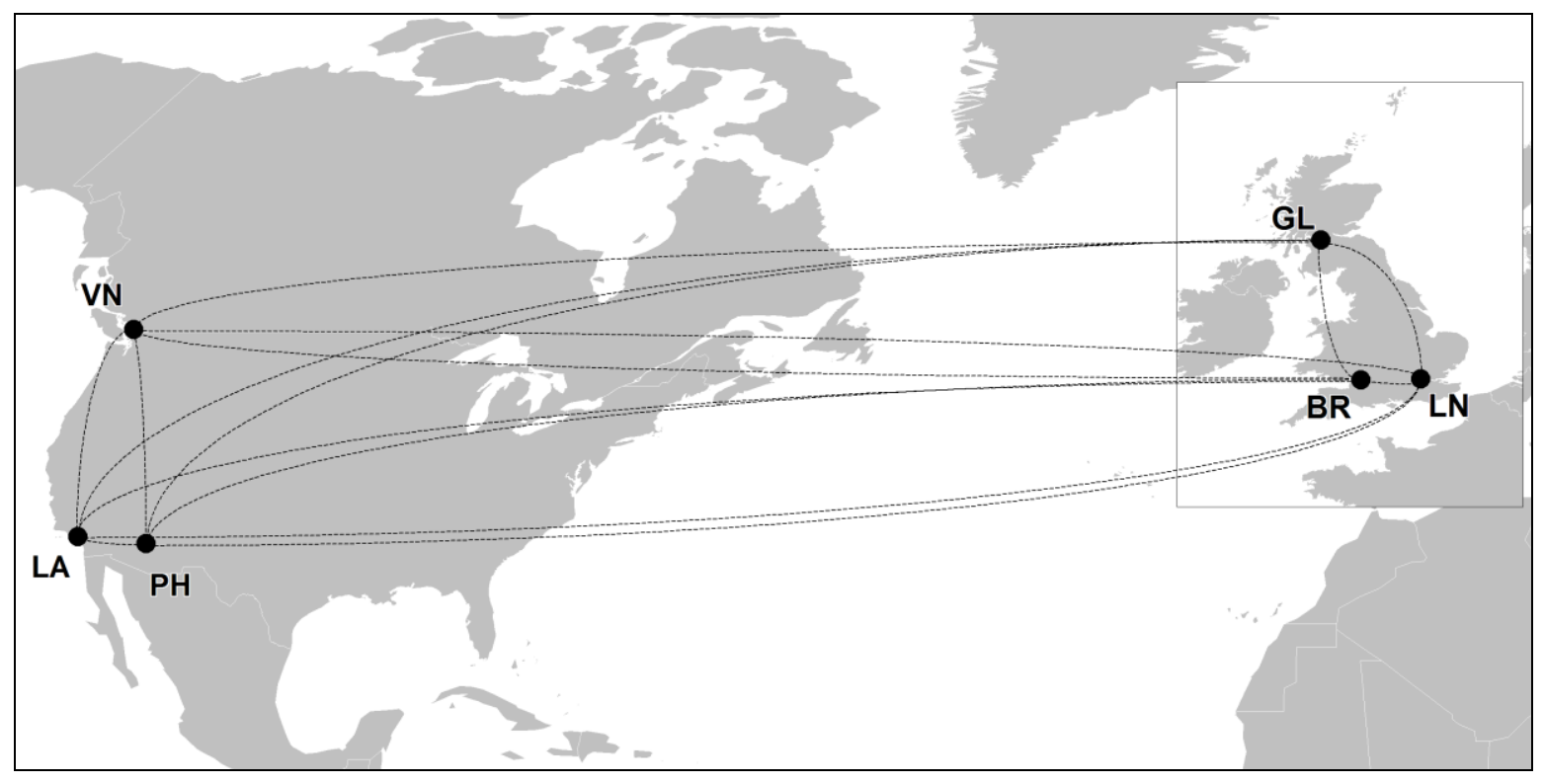

City codes: BR-Bristol; GL-Glasgow; LA-Los Angeles; LN-London; PH-Phoenix; VN-Vancouver. 
Figure 2: Global urban networks of recording, UK digital music market

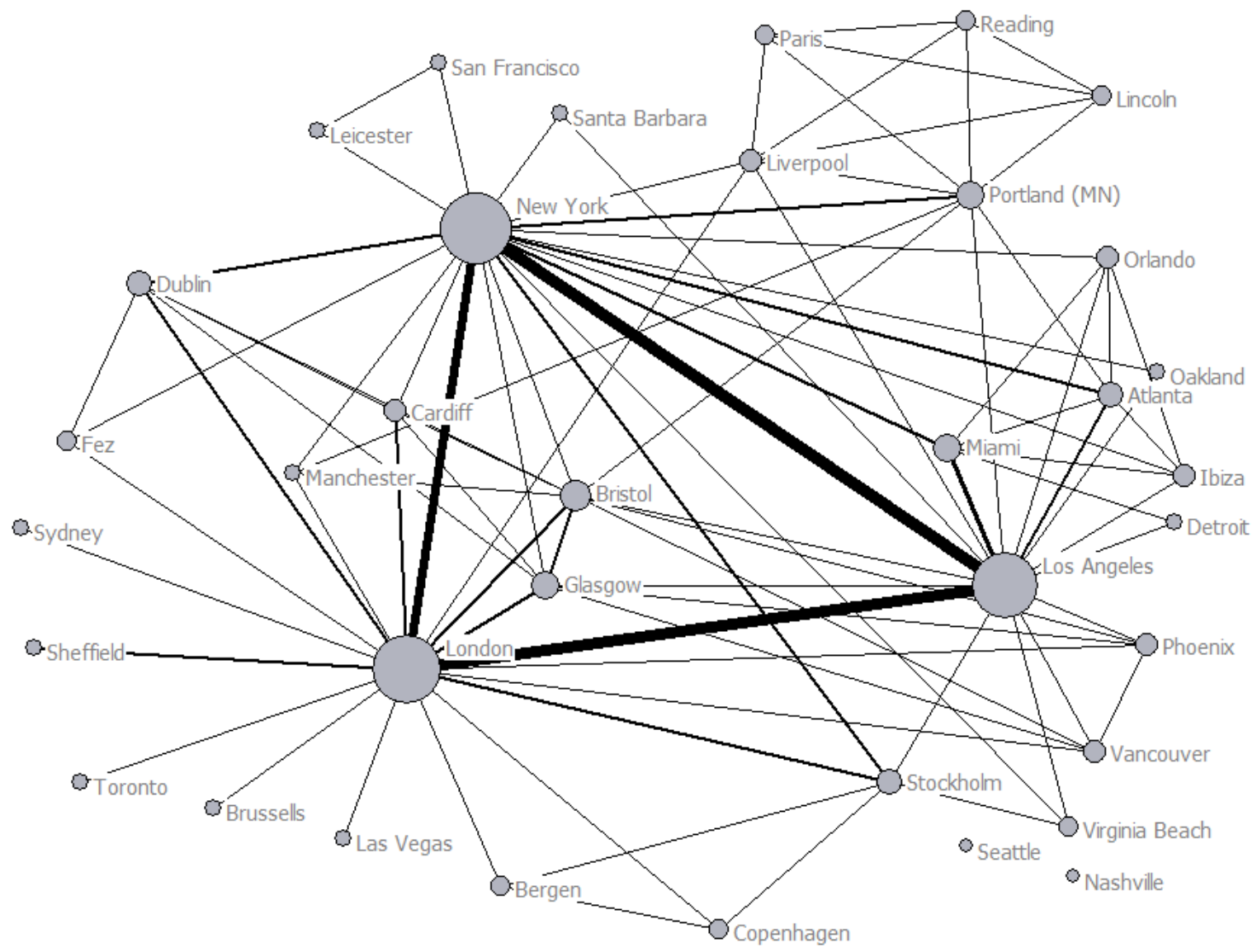

Note: Tie strength is based on number of inter-city links; the size of the nodes is based on the total connectivity of the city. 
Figure 3: Global urban networks of recording, US national market

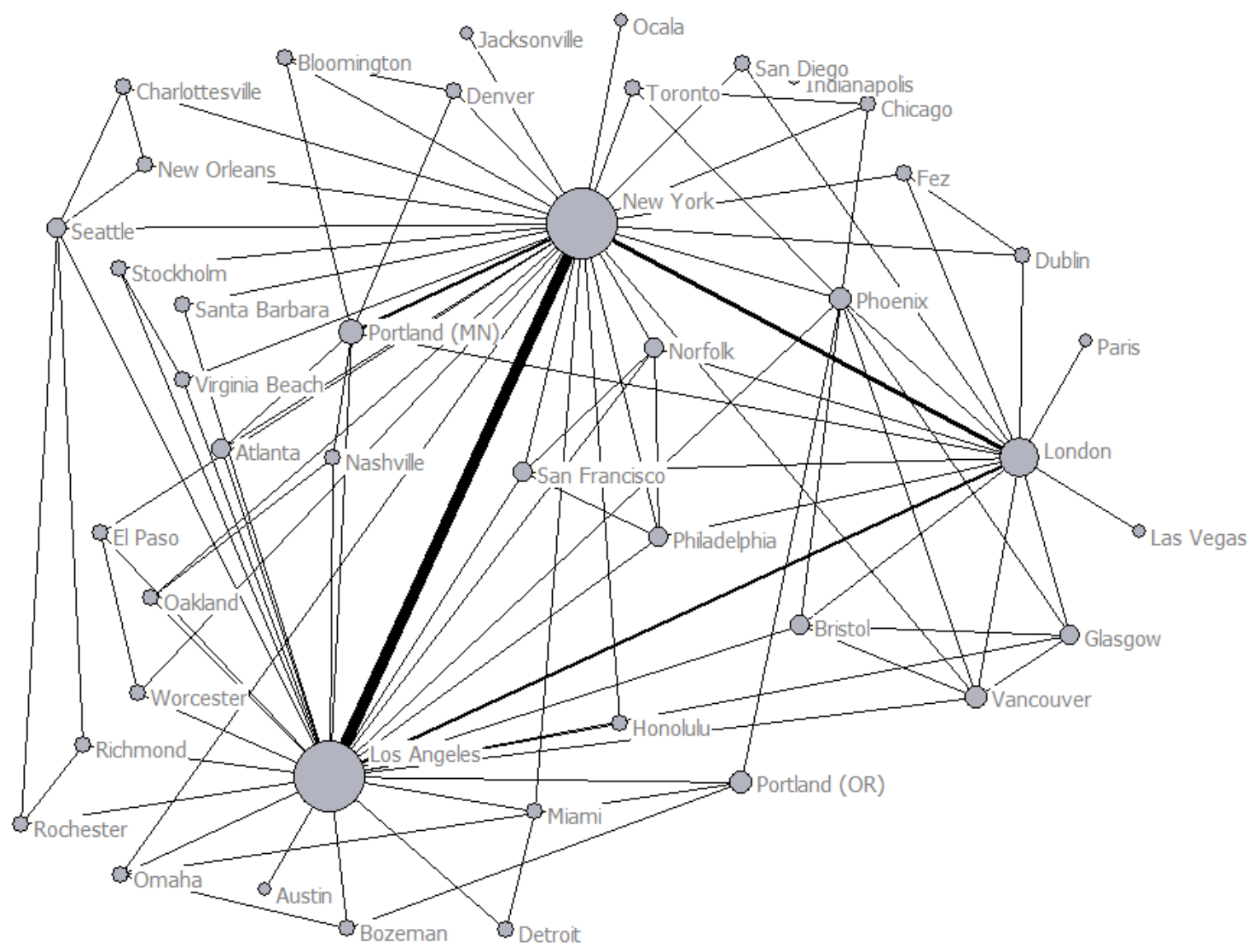

Note: Tie strength is based on number of inter-city links; the size of the nodes is based on the total connectivity of the city. 
Table 1: Top 5 cities ranked by output of albums; UK digital music market

\begin{tabular}{lll}
\hline Rank & City & $\begin{array}{c}\text { Albums output from the city } \\
\text { (\% of total number of albums) }\end{array}$ \\
\hline 1 & London & $52 \%$ \\
2 & Los Angeles & $38 \%$ \\
3 & New York & $36 \%$ \\
4 & Cardiff & $7 \%$ \\
5 & Bristol & $5 \%$ \\
$\sim$ & Glasgow & $5 \%$ \\
$\sim$ & Portland (MN) & $5 \%$ \\
$\sim$ & Miami & $5 \%$ \\
$\sim$ & Dublin & $5 \%$ \\
$\sim$ & Stockholm & $5 \%$ \\
\hline
\end{tabular}

Note: A single album can be considered to be output from more than one city where the album is produced within a creative project network of cities. 
Table 2: Top 5 cities ranked by output of albums; US digital music market

\begin{tabular}{llc}
\hline Rank & City & $\begin{array}{c}\text { Albums output from the city } \\
\text { (\% of total number of albums) }\end{array}$ \\
\hline 1 & Los Angeles & $58 \%$ \\
2 & New York & $46 \%$ \\
3 & London & $25 \%$ \\
4 & Nashville & $10 \%$ \\
5 & Portland (MN) & $8 \%$ \\
\hline
\end{tabular}

Note: A single album can be considered to be output from more than one city where the album is produced within a creative project network of cities. 
Table 3: Top cities ranked by total number of connections, UK digital music market

\begin{tabular}{llll}
\hline Rank & City & Total connections & Highest connectivity \\
\hline 1 & New York & 38 & 9 (Los Angeles) \\
& & & 6 (London) \\
2 & London & 37 & 8 (Los Angeles) \\
& & & 6 (New York) \\
3 & Los Angeles & 35 & 9 (New York) \\
4 & Bristol & 12 & 8 (London) \\
5 & Glasgow & 10 & 2 (London, Glasgow) \\
$\sim$ & Portland (MN) & 10 & 2 (London, Bristol) \\
& & & 2 (New York) \\
7 & Miami & 9 & 3 (Los Angeles) \\
8 & Atlanta & 8 & 2 (New York) \\
$\sim$ & Dublin & 8 & 2 (New York, Los Angeles) \\
$\sim$ & Stockholm & 8 & 2 (New York, London) \\
\hline & & & 2 (New York, London) \\
& & &
\end{tabular}


Table 4: Top cities ranked by total number of connections; US digital music market

\begin{tabular}{llll}
\hline Rank & City & Total connections & Highest connectivity \\
\hline 1 & New York & 54 & 18 (Los Angeles) \\
& & 5 (London) \\
2 & Los Angeles & 53 & 18 (Los Angeles) \\
& & & 4 (London) \\
3 & London & 23 & 5 (New York) \\
4 & Portland (MN) & 11 & 4 (Los Angeles) \\
5 & Phoenix & 9 & 3 (New York) \\
6 & Portland (OR) & 7 & 1 \\
7 & Vancouver & 7 & 1 \\
8 & Seattle & 6 & 2 (Los Angeles) \\
\hline
\end{tabular}


Table 5: Centrality measure rankings for London, New York and Los Angeles; UK digital music market

\begin{tabular}{lccc}
\hline City & $\begin{array}{c}\text { Bonacich } \\
\text { centrality rank }\end{array}$ & $\begin{array}{c}\text { Bonacich power } \\
\text { rank }\end{array}$ & $\begin{array}{c}\text { Flow betweeness } \\
\text { centrality rank }\end{array}$ \\
\hline London & 3 & $\mathbf{1}$ & $\mathbf{1}$ \\
New York & 2 & 2 & 2 \\
Los Angeles & $\mathbf{1}$ & 3 & 3 \\
\hline
\end{tabular}


Table 6: Centrality measure rankings for London, New York and Los Angeles; US digital music market

\begin{tabular}{lccc}
\hline City & $\begin{array}{c}\text { Bonacich } \\
\text { centrality rank }\end{array}$ & $\begin{array}{c}\text { Bonacich power } \\
\text { rank }\end{array}$ & $\begin{array}{c}\text { Flow betweeness } \\
\text { centrality rank }\end{array}$ \\
\hline New York & $\mathbf{1}$ & $\mathbf{1}$ & $\mathbf{1}$ \\
Los Angeles & 2 & 2 & 2 \\
London & 3 & 3 & 3 \\
\hline
\end{tabular}


Table 7: Top 5 mastering studios in networks of musical production, UK digital music market

\begin{tabular}{llc}
\hline Mastering studio & City & $\begin{array}{c}\text { Number of albums mastered } \\
\text { (\% of total number of albums) }\end{array}$ \\
\hline Metropolis Studios & London & $20 \%$ \\
Sterling Sound & New York & $13 \%$ \\
Bernie Grudman Mastering & Los Angeles & $8 \%$ \\
Gateway Mastering & Portland (MN) & $7 \%$ \\
Masterdisk & New York & $7 \%$ \\
\hline
\end{tabular}


Table 8: Top 5 mastering studios in networks of musical production, US digital music market

\begin{tabular}{llc}
\hline Mastering studio & City & $\begin{array}{c}\text { Number of albums mastered } \\
\text { (\% of total number of albums) }\end{array}$ \\
\hline Sterling Sound & New York & $27 \%$ \\
Bernie Grudman Mastering & Los Angeles & $13 \%$ \\
Gateway Mastering & Portland (MN) & $10 \%$ \\
Marcussen Mastering & Los Angeles & $8 \%$ \\
Metropolis Studios & London & $8 \%$ \\
\hline
\end{tabular}

